\title{
Nature Clinical Practice Nephrology: a progress report
}

\author{
Suzanne J Farley and Robert W Schrier
}

Launching a new journal is a major undertaking. It's easy for editors to get caught up in the day-to-day pressures of sending each monthly issue to the printers on time, and to neglect post-publication follow-up. At Nature Clinical Practice Nephrology we understand the importance of continually assessing our progress. Are we fulfilling our goal of translating the latest findings into clinical practice? Does this goal meet the needs of our target audience of practicing nephrologists?

We have several means of garnering feedback. Comments come from authors and peerreviewers during correspondence with the editors, and from attendees at conferences. Happily, the comments received via these means have been overwhelmingly positive. But a more formal-and anonymous - approach is necessary if a true representation of opinions is to be collated.

To this end, Nature Clinical Practice Nephrology invited both readers and authors to complete an online survey. We had an unprecedented number of responses-almost 700-to the reader survey, which was distributed primarily to members of the International Society of Nephrology who receive the journal as a benefit of society membership. The majority of respondents were members of our target audience; that is, physicians who regularly see patients.

The take-home message is that Nature Clinical Practice Nephrology is successfully fulfilling its aims; on average, about $80 \%$ of respondents gave positive responses to the questions posed. Readers from a wide range of countries found the journal very useful to their clinical practice. Most thought that articles were an appropriate length for the subject matter covered, and pitched at the right level of expertise. Coverage of different subspecialties is satisfactory, as is the balance between basic science and clinical material. Interestingly, in this online era, most readers still prefer to peruse the print version of the journal. A significant proportion of print copies are passed from subscriber to colleagues.

\section{Desirable additional \\ features \\ include \\ advanced \\ online \\ publication, moderated \\ post- \\ publication \\ discussion of \\ articles, and \\ publication \\ of clinical \\ guidelines}

SJ Farley is Editor, and RW Schrier is Editorin-Chief, of Nature Clinical Practice Nephrology.

\section{Competing interests}

The authors declared they have no competing interests.

www.nature.com/clinicalpractice doi:10.1038/ncpneph0250
Many respondents took the time to provide constructive suggestions, the feasibility of which will be followed up by Nature Clinical Practice staff. Desirable additional features include advanced online publication (already scheduled for roll-out), moderated postpublication discussion of articles (a form of which is already available through our online correspondence section), and publication of clinical guidelines and news stories.

There were requests for the journal to publish more articles on pediatrics, interventional nephrology, peritoneal dialysis, pathology, stones, transplantation and hypertension. It is, of course, very challenging to cover every subspecialty to everybody's satisfaction in a 60-page monthly issue, but watch out for more articles on these topics in upcoming editions.

There have been fewer responses to our author survey, but some useful feedback has been received. Most of those who have contributed to Nature Clinical Practice Nephrology have appreciated the guidance provided by editorial staff, and found using the online manuscript submission service straightforward. The layout of articles in print and online was pleasing to the majority, as was the availability of figures for download as PowerPoint slides. The word limits on some article types were considered too restrictive by some authors. As such, these limits have been relaxed for Reviews. We have also initiated a project to investigate a redesign of the Practice Point section, so that authors of the Commentaries can have more than one printed page to get their point across.

Flexibility to respond to the changing needs of our readers is essential to the ongoing success of Nature Clinical Practice Nephrology. We are committed to this aim, and sincerely appreciate the feedback you have given. If you have any further comments, please contact us at any time (via email to ncpneph@nature.com or the 'Contact the journal' link on our website). 